\title{
Article \\ Wireless Power Transfer Using Harvested Radio Frequency Energy with Magnetic Resonance Coupling to Charge Mobile Device Batteries
}

\author{
Neetu Ramsaroop and Oludayo O. Olugbara *(1) \\ ICT and Society Research Group, South Africa Luban Workshop, Durban University of Technology, Durban 4000, \\ South Africa; neetu43r@gmail.com \\ * Correspondence: oludayoo@dut.ac.za
}

check for updates

Citation: Ramsaroop, N.; Olugbara, O.O. Wireless Power Transfer Using Harvested Radio Frequency Energy with Magnetic Resonance Coupling to Charge Mobile Device Batteries. Appl Sci. 2021, 11, 7707. https://doi.org/ 10.3390/app11167707

Academic Editor: Cheonshik Kim

Received: 29 June 2021

Accepted: 19 August 2021

Published: 21 August 2021

Publisher's Note: MDPI stays neutral with regard to jurisdictional claims in published maps and institutional affiliations.

Copyright: (c) 2021 by the authors. Licensee MDPI, Basel, Switzerland. This article is an open access article distributed under the terms and conditions of the Creative Commons Attribution (CC BY) license (https:/ / creativecommons.org/licenses/by/ $4.0 /)$.

\begin{abstract}
This research paper presents the design of a wireless power transfer (WPT) circuit integrated with magnetic resonance coupling (MRC) and harvested radio frequency (RF) energy to wirelessly charge the battery of a mobile device. A capacitor $(100 \mu \mathrm{F}, 16 \mathrm{~V})$ in the RF energy harvesting circuit stored the converted power, and the accumulated voltage stored in the capacitor was $9.46 \mathrm{~V}$. The foundation of the proposed WPT prototype circuit included two coils (28 AWG) - a transmitter coil, and a receiver coil. The transmitter coil was energized by the alternating current (AC), which produced a magnetic field, which in turn induced a current in the receiver coil. The harvested RF energy $(9.46 \mathrm{~V})$ was converted into AC, which energized the transmitter coil and generated a magnetic field. The electronics in the receiver coil then converted the AC into direct current (DC), which became usable power to charge the battery of a mobile device. The experimental setup based on mathematical modeling and simulation displayed successful charging capabilities of MRC, with the alternate power source being the harvested RF energy. Mathematical formulae were applied to calculate the amount of power generated from the prototype circuit. LTSpice simulation software was applied to demonstrate the behavior of the different components in the circuit layout for effective WPT transfer.
\end{abstract}

Keywords: battery; coupling; energy; frequency; magnetic; mobile; power; radio; receiver; resonance; transmitter

\section{Introduction}

The fourth or fifth industrial revolution is the future of our society, and the requirement for wirelessly charging the batteries of electronic devices has motivated power electronic engineers to find innovative ways to overcome the future charging infrastructure problem [1]. The electronic product designers and engineers previously experienced power challenges in the form of continuously supplying power, recharging batteries, optimizing the location of sensors, and dealing with rotating and moving joints in electronic machinery. Although these challenges remain unresolved, new demands that arise from the increased use of mobile devices and the operation of these devices in dirty or wet environments mean that designers require new approaches for supplying power to electronic equipment [2].

The vision of wireless power transfer (WPT) provides a practical resolution to the challenges often experienced with the incessant contact-charging or wired cable charging of mobile device batteries. The conjecture and evidence of WPT originated in the early 19th century. The idea of transferring power wirelessly was initially suggested by Nikolas Tesla in 1891 with his Tesla coil invention [3]. The theory of electromagnetism states that electromagnetic waves move at the speed of light and that light is a wave [4]. Power can be wirelessly transmitted up to certain distances using a transmitter coil and a receiver coil. This technique can make a dramatic change in the field of electrical engineering in the nearest future. It can cause breakthrough innovation or disruptive innovation by 
eliminating the use of physical wires, different cables, connectors, and power cords that are currently pervasively used to transmit power up to large distances [5]. In addition, the magnetic resonance coupling (MRC) would be a practical resolution for wirelessly charging the batteries of pacemakers fitted inside the body of heart patients to eliminate the endless replacement of pacemaker batteries [6]. WPT is trending in the medical field [7] through implementing a wireless charging method for active implantable medical devices (AIMDs). These devices include mechanical pumps that are responsible for pumping blood within the body of a patient, a Doppler flow meter that monitors the flow of blood for signs of clotting, and endoscopic capsules that detect or diagnose health risks related to the gastrointestinal (GI) tract [8]. MRC can be used for different real-life applications like charging the batteries of mobile devices, including the batteries of laptops, iPods, aviation devices, wind turbines, and automation systems [8].

The method of charging the batteries of mobile devices will be made more convenient when WPT is finally accomplished, because the method will eliminate the necessity to regularly plug a cord into an electrical outlet [9-11]. In addition, as power can be transferred constantly to the batteries of mobile devices, the battery size can be reduced significantly. Moreover, the danger of being electrocuted because of the wear and tear of old power cords will be avoided completely. This is because the process of handling a power cord would not be necessary, thus making the charging process safer. The WPT system must satisfy three essential conditions of high efficiency, large air gaps, and high power in order to achieve wireless charging [12]. There are a few challenges that need to be considered when utilizing the WPT system to charge the batteries of electronic devices. They include an interruption to the frequency of less than $150 \mathrm{kHz}$, WPT charging points, and appropriate charging frequencies for the various devices. These should be considered with the charging expectations of the WPT system [13]. Extensive research has been conducted on WPT used for charging electric vehicles. The agglutination of WPT with MRC was used to charge the wheel motion in electric vehicles [14]. The current research trends include using a contactless energy harvester to power the condition of monitoring sensors in a smart grid to harvest more energy [15]. A major issue experienced with using WPT to charge electric vehicles was stated in various publications as stray magnetic fields. The existence of stray magnetic fields within the WPT charging field results in the charging magnetic field becoming weak [16]. Studies have been conducted on measuring the stray magnetic fields for improving the charging apparatus so as to limit stray magnetic fields [17-20].

Radiofrequency (RF) energy harvesting is an emerging technology and an intriguing research area that promises to produce enough power to run miniaturized wireless devices and supply power to wireless sensor networks (WSNs). The RF energy harvesting system aimed to convert the received ambient RF energy into usable DC power. The evolution of RF energy scavenging in free space originated in the late 1950s with a microwave-powered helicopter [21]. The existence of electromagnetic radiation started with the research conducted by Heinrich Hertz, who proved the presence of electromagnetic radiation and radio waves in experiments from 1886 to 1888 [22]. Popular energy harvesters used today include solar cells, wind, waves from the ocean, thermal energy, and vibration [23]. Although these are extensively used, energy harvesters have limited capabilities, such as high installation costs, and solar cells will not work efficiently in cloudy weather. The types of devices that produce RF signals from which energy can be harvested according to operating distances are Bluetooth (2.40 to $2.48 \mathrm{GHz}$ ), WIFI (2.40 GHz to $5.8 \mathrm{GHz})$, and cellular technology (700 MHz to $2.7 \mathrm{GHz}$ ) [24]. The MRC offers freedom from the annoying wires during charging, and when combined with the RF energy harvesting as an alternate power source [25], it becomes an efficient method for charging the batteries of mobile devices. There are various studies on WPT techniques, MRC, and related components, but limited research has been conducted on the wireless transfer of RF harvested power using the MRC method. This research contributes to filling this literature void of the dearth of studies on the application of MRC for the wireless transfer of RF harvested power to charge the batteries of mobile devices. 


\section{Methods}

The mathematical modeling and simulation (M\&S) research method [26] formed the basis for implementing a prototype system to test the viability of a complete WPT circuit. M\&S assisted in acquiring the necessary information about the behavior of the WPT prototype through simulation and mathematical equations before the physical implementation, testing, and deployment. The LTspice simulation software (Analog Devices Inc., Wilmington, MA, USA) was utilized to analyze the test results of the WPT prototype circuit [27]. The variables considered for the energy harvesting circuit were distance, antenna type, and amount of energy harvested based on the feasibility of the circuit model. The variables considered for the MRC [28] circuit were the resistance and conductivity of the copper wire. The relevant formulae were applied to display the quality factor aspect of the complete WPT prototype circuit. It is practical to take into consideration the RF energy harvesting system, the circuitry of the magnetic resonant system, and the signal strength of the receiving antenna (Yagi-Uda) with a frequency range from $30 \mathrm{MHz}$ to $3 \mathrm{GHz}$. The factors affecting the efficiency of the wireless power system were based on the coil design configuration, transmission distance, and coupling. A less efficient system will generate more emissions and result in less power passing through to the receiver device or load [29].

The prototype system consisted of the RF energy harvesting circuit initially tested in a previous study [30], which represented the input to the WPT system utilizing MRC. Figure 1 presents the block diagram for the WPT prototype system. The received RF signals are converted to electrical power through the RF energy harvester circuit (A) [30]. The power management system (B) sends the converted electrical power to be used as the input load (C) to the transmitting coil (D) in the WPT system. It consists of single transistor oscillator attached to the transmitting coil [31]. The receiving coil (E) transfers the electrical power $(\mathrm{AC})$, referred to as the load to be converted by the rectifier $(\mathrm{F})$ into DC power, which is stored in the storage capacitor $(\mathrm{G})$. The voltage regulator $(\mathrm{H})$ transfers the required $\mathrm{DC}$ power wirelessly through the MRC to the battery of a miniaturized electronic device (I) for charging. The components used for the initial magnetic resonance prototype circuit consisted of 22 AWG magnetic wire, 15 turns magnetic wire (receiver coil (D)), 7.5 turns of the magnetic wire with a looped tap $(3 \mathrm{~cm})$, and another 7.5 turns of magnetic wire (transmitting coil (E)), each with a diameter of $5 \mathrm{~cm}$. The resistivity, resistance, conductance, area, and length of coils were taken into consideration because they impact the flow of voltage through the circuit. The RF energy harvesting circuit included the rectifier component, similar to the full bridge rectifier circuit [30].

The block diagram (Figure 1) can be divided into two components-the RF energy harvesting circuit and wireless power charging circuit. The RF energy harvesting circuit consisted of a voltage rectifier component (full-wave), Yagi-Uda antenna connection with a frequency range of $30 \mathrm{MHz}$ to $3 \mathrm{GHz}$ (RG-5 coaxial cable), and ground connection, which is a straight copper cable attached to a metal pole inserted $6 \mathrm{~m}$ into the ground [30]. The rectifier component within the RF energy harvesting circuit is responsible for converting the RF signals from the antenna to DC voltage [25,30,32]. The wireless power charging circuit includes the magnetically coupled coils shown in Figure 2, the transmitting coil (D) connected to single transistor oscillator, the receiving coil (E) with the rectifier (F) to convert AC to DC [33], and a capacitor (G) to smooth or filter the pulsating DC output after rectification and to store the converted voltage. Rectification comprises a bridge rectifier attached to the receiving coil to make the conversion from AC to DC [34-36]. The responsibility of the voltage regulator is to normalize the voltage to the load. The voltage regulator was included to maintain a constant voltage to the load for charging, but should this component be removed, the WPT circuit will still function. 


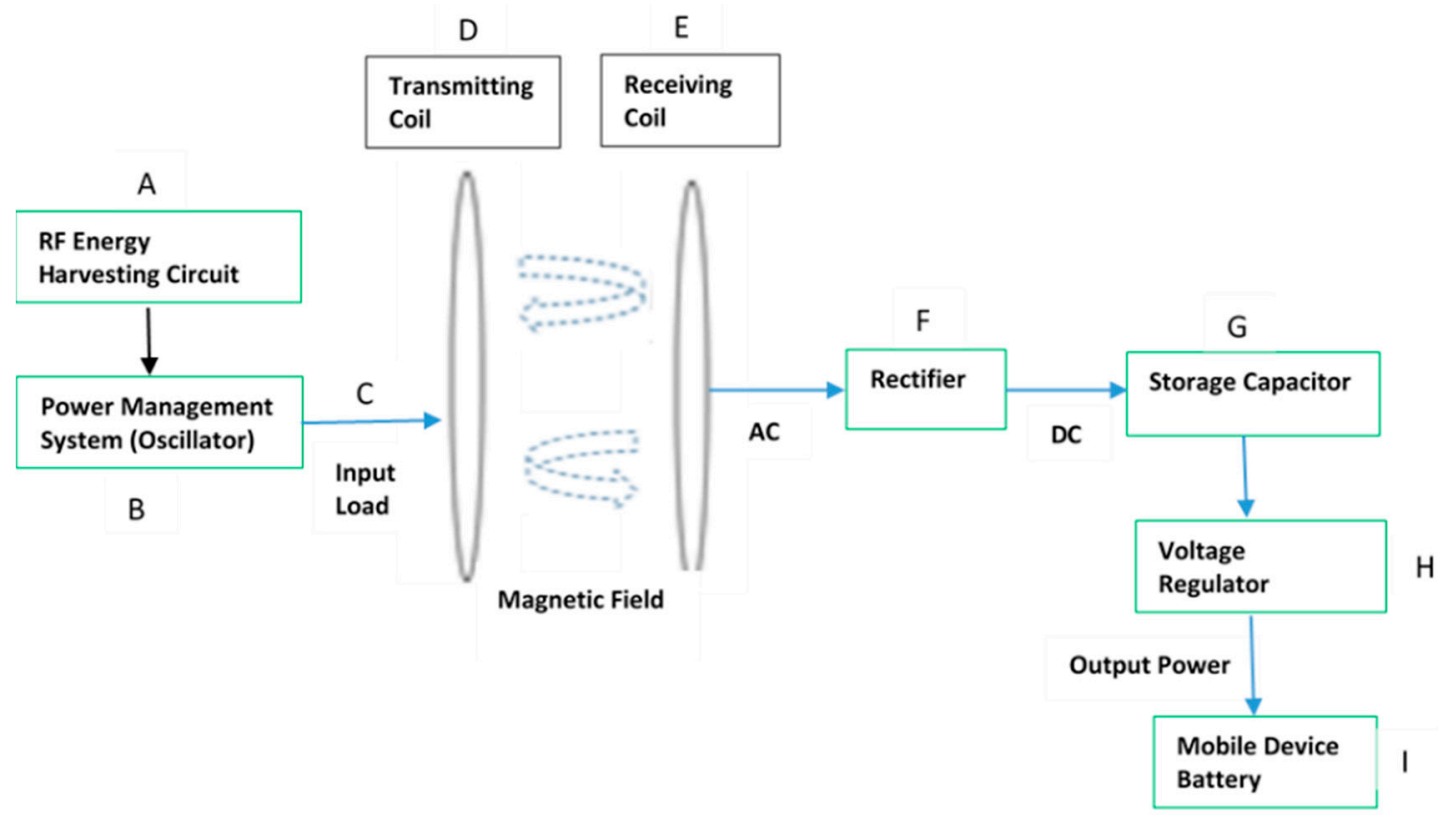

Figure 1. Block diagram for the wireless power transfer prototype circuit.

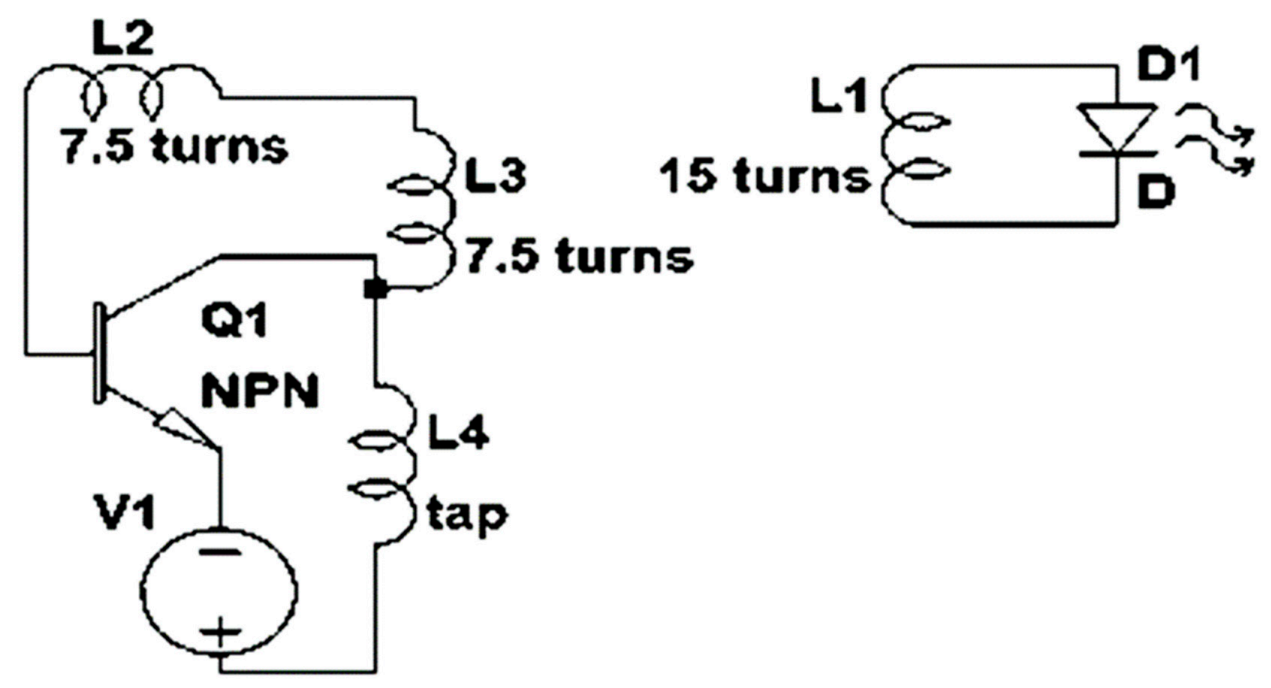

Figure 2. Magnetic resonance coupling circuit.

\section{Simulation}

The mutual inductance represented in Figure 3 is the operating principle of all electrical components interacting with the magnetic field. In this episode, all the components from the primary (transmitter) coil interact with the components of the secondary (receiving) coil, as presented in the block diagram of the WPT charging circuit (Figure 1).

The mutual inductance of coils was taken into consideration to analyze the WPT circuit by applying Equation (1).

$$
M=k \sqrt{L p L s}, \quad 0 \leq k \leq 1
$$

where $L p$ and $L s$ represent the equivalent inductance in the primary (transmitter) and secondary (receiver) coils, respectively; $k$ is the coupling coefficient that measures the magnetic coupling between the two coils; and $M$ is the mutual inductance. The magnetic flux $(\varnothing)$ common to both the transmitting and receiving coils are represented by $k \varnothing_{T}$, where $\varnothing_{\mathrm{T}}$ is the total magnetic flux at a $0^{0}$ angle. The magnetic flux is only presented in one 
coil, it is not included in the energy transfer and is represented by $(1-k) \varnothing_{\mathrm{T}}$. The overall inductance $L$ can be calculated using the following equation.

$$
L=\frac{n^{2} \times \mu_{0} \times A}{L_{e}}
$$

where $n$ is the number of turns in the coil, $\mu_{0}$ is the permeability of free space as measured in the unit of Henry $(\mathrm{H})$. The parameter " $A$ " is the cross-sectional area of the coil measured in square meters $\left(\mathrm{m}^{2}\right)$ and $L_{e}$ is the length of coil measured in the unit of a meter $(\mathrm{m})$. The coupling coefficient, $k$, can be calculated from Equation (1) as follows.

$$
k=\frac{M}{\sqrt{L p L s}}
$$

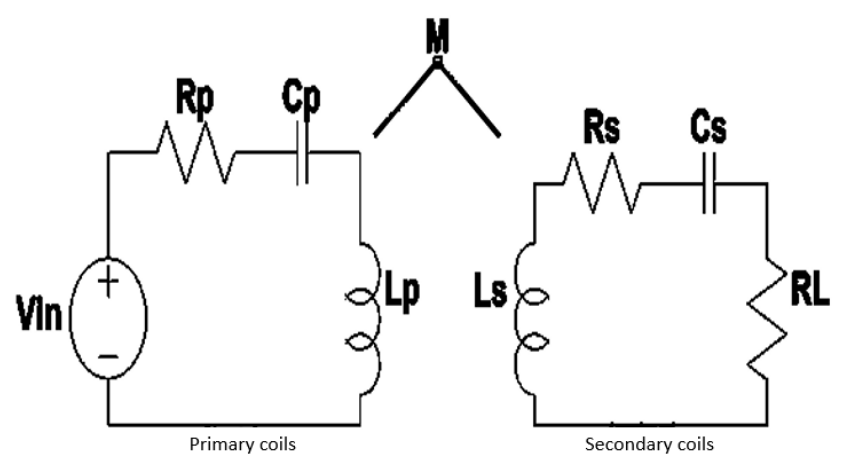

Figure 3. Mutual inductance of the primary and secondary coils.

The possible conclusion for the value of $k$ satisfying $0 \leq k \leq 1$ is that when the value is less than 0.5 , the coils are loosely coupled; when the value is greater than 0.5 , the coils are tightly coupled; and when the value equals 1.0, the coils are magnetically coupled. It was necessary to separate the coupled circuit and to include the dependent voltage sources to each coupling circuit in further analyses. The dependent voltage sources are replacing the coupling between the two circuits. The current running through the secondary coil (receiving), $I_{2}$, can be calculated as follows.

$$
I_{2}=\frac{-j \omega M I_{1}}{Z_{s}}
$$

where $I_{1}$ is the current running through the primary coil (transmitting), $j \omega M I_{2}$ is the dependent voltage of the primary coil, $j \omega M I_{1}$ is the dependent voltage of the secondary coil, and $Z_{s}$ is the reflective impedance that considers $L_{s}$, as given by Equations (5)-(8). The parameter $C_{s}$ represents the capacitance at secondary coils; $R_{L}$ represents the output voltage load passed to the rectifier, storage capacitor, and/or voltage regulator to charge the battery of a mobile device; $R s$ represents the resistance at the secondary coil; and $Z_{R i}$ is the overall reflective impedance of both coils.

$$
\begin{gathered}
Z_{s}=R_{L}+\frac{1}{j \omega C_{s}}+j \omega L_{s}+R_{s} \\
j \omega M I_{2}=\frac{\omega^{2} M^{2}}{Z_{s}}+I_{1} \\
Z_{R i}=\frac{(\omega M)^{2}}{Z_{s}} \\
Z_{R i}=\frac{[\omega k \sqrt{L p L s}]^{2}}{Z_{s}}
\end{gathered}
$$


The value at $I_{1}$ is at a maximum when $Z_{s}$ is at a minimum. The total resistance $\left(R_{L}{ }^{\prime}\right)$ of the circuit can be obtained based on the total load $\left(R_{L}\right)$ and resistance at the secondary coil $\left(R_{S}\right)$ according to the following equations with $V_{i n}=\omega_{0}$, where $C p$ represents the capacitance at the primary coil.

$$
\begin{gathered}
\omega_{o}=\frac{1}{\sqrt{L_{p} C_{p}}}=\frac{1}{\sqrt{L_{s} C_{s}}} \\
\frac{\left(\omega_{o} M\right)^{2}}{R_{L}{ }^{\prime}}=\frac{k^{2} \omega_{o}^{2} L}{R_{L}{ }^{\prime}} \\
R_{L}{ }^{\prime}=R_{L}+R_{s}
\end{gathered}
$$

where the parameter $P$ is the power given by the Equations (12) and (13).

$$
\begin{gathered}
P=I_{2}{ }^{2} R_{L} \\
P=I_{2}{ }^{2} \frac{\left(\omega_{0} M\right)^{2}}{R_{L}{ }^{\prime}} \cdot \frac{R_{L}}{R_{L}+R_{S}}
\end{gathered}
$$

The resistivity equation [37] of copper wire is a measure of how intensely the copper wire coils can oppose the flow of electric current through the copper coils. The resistivity can be calculated as follows.

$$
\rho=\frac{R A}{l_{e}}
$$

where $\rho$ is the resistivity, $A$ is the area of the copper wire, $l_{e}$ is the length of the copper wire, and $R$ is the resistance. The voltage resistance [37] of the copper wire is the opposition of voltage flow through the copper wire coils. The resistance is given according to the following equation.

$$
R=\frac{\rho l_{e}}{A}
$$

where $R$ represents the resistance value in ohms $(\Omega), \rho$ is the resistivity, $l_{e}$ is the length of the copper coils, and $A$ is the area. The conductance of the copper wire determines the amount of voltage that flows through the copper wire. It is computed using the following equation [37].

$$
G=\frac{A}{\rho l_{e}}
$$

where $G$ represents the conductance value, $A$ is the area of the copper wire, $\rho$ is the resistivity, and $l_{e}$ is the length of the copper wire. The conductance was affected by the resistivity of the copper wire, which is the total resistance of the copper wire. The larger the resistivity of the copper wire, the lower conductance it possesses in a circuit. The lower the resistivity, the greater conductance it possesses. The coupling constant does not include the number of turns in a coil, which defines the magnetic field to be formed for a given current. The coupling constant includes how the lines of magnetic force created by one coil relate to the second coil. The coupling constant amid two air-spaced coils is dependent on the physical size and nature of the air space. Hence, to obtain the best coupling between the transmitting and receiving coils in the WPT circuit, the size and spatial relationships of the coils can only be changed. The average direct current (DC) output voltage in the energy harvesting circuit, represented in the block diagram (Figure 1) across the sine wave in the full-wave rectifier circuit, is calculated using the following equation [32].

$$
V a=\frac{2 V p}{\pi}
$$

where $V a$ is the average voltage and $V p$ is the peak load voltage, or the input voltage divided by $\pi$. Electrical resistance is the opposition to the flow of voltage within the full-wave rectifier circuit and this was calculated using the following Ohm's law [38]. 


$$
R=\frac{V}{I}
$$

where $R$ represents the resistance value in ohms $(\Omega), V$ is the voltage, and $I$ is the current of the resistors in amps (A). The input voltage was set at $6 \mathrm{~V}$, which is the target voltage intended to be acquired by the actual RF energy harvesting circuit in order to initiate the charging of the battery of a mobile device. It is represented by a constant sine wave from the start-up to $2 \mathrm{~s}$ timeframe, as depicted by trace analysis in Figure 4. Approximately $5 \mathrm{~V}$ is required to charge the battery of a mobile device based on the output voltage of most of the mobile device chargers.

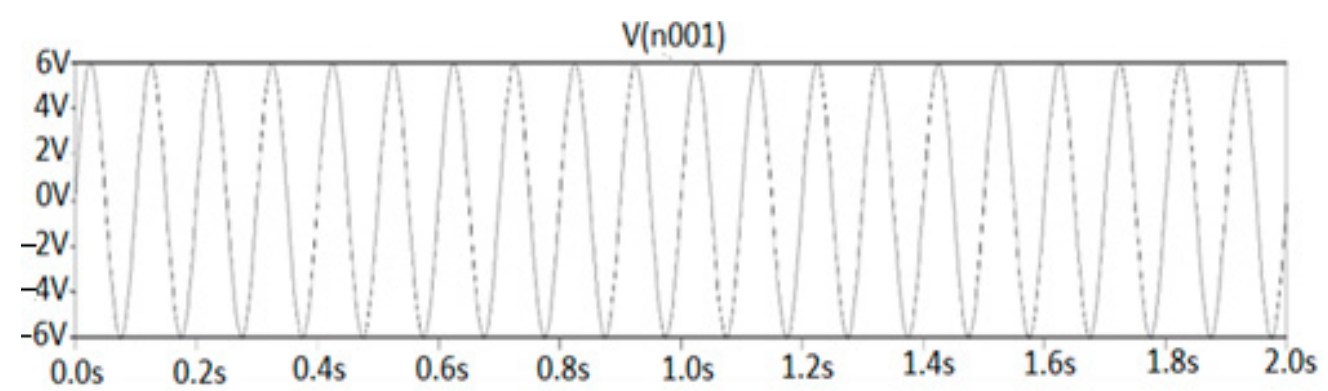

Figure 4. Trace analysis of the input voltage set at $6 \mathrm{~V}$ to initiate a charge.

The output voltage after the transient analysis was conducted is depicted in Figure 5, representing $5.4 \mathrm{~V}$, which clearly shows a voltage drop of $0.6 \mathrm{~V}$. The transient analysis monitors the changes in the state of the circuit from one point in time to another. The output voltage over the similar $2 \mathrm{~s}$ timeframe is shown in Figure 5.

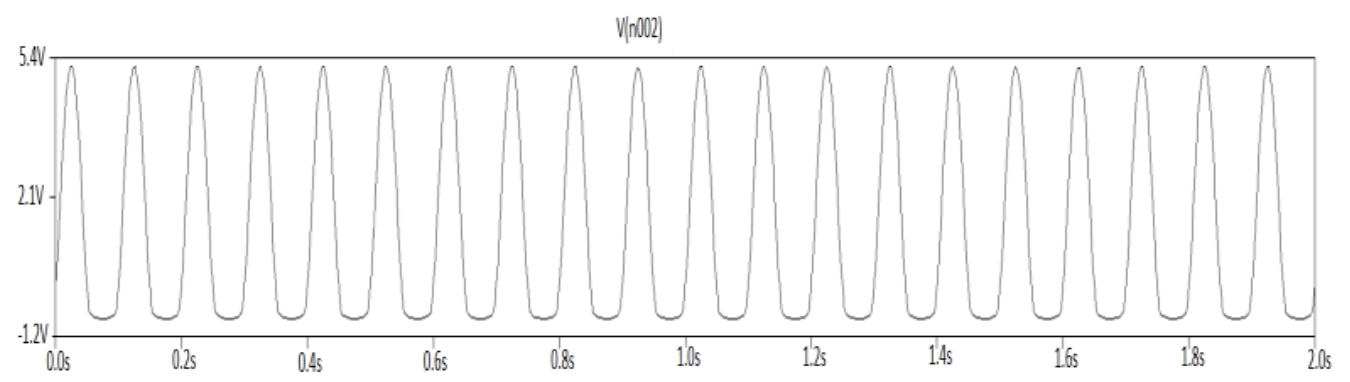

Figure 5. The predicted output voltage of the RF energy harvesting circuit.

Table 1 displays the parameter symbol, brief definition, unit of measurement, and parameter value considered in the simulation experiments of this study.

Table 1. Simulation Parameters.

\begin{tabular}{cccc}
\hline Parameter Symbol & Parameter Definition & Unit of Measurement & Parameter Value \\
\hline$n$ & Number of turns in coil & $\mathrm{n}^{2}$ & 227 \\
\hline$H$ & Permeability of free space & $\mu_{0}$ & 1.26 \\
\hline$A$ & Cross-sectional area of coil & $\mathrm{m}^{2}$ & 0.05 \\
\hline$L_{e}$ & Length of coil & $\mathrm{m}$ & 2.70 \\
\hline$M$ & Mutual inductance & $\mathrm{H}$ & 2.62 \\
\hline$L$ & Inductance & $\mathrm{H}$ & 2.62 \\
\hline$R$ & Resistance & $\Omega$ & 2.29 \\
\hline$k$ & Coupling coefficient & $\mathrm{k}$ & 1.00 \\
\hline$V i n$ & Input voltage & $\mathrm{V}$ & 6.00 \\
\hline$S a$ & Average voltage & $\mathrm{V}$ & 3.82 \\
\hline
\end{tabular}




\section{Results and Discussion}

The prototype WPT circuit included two copper coils of 28 AWG magnetic wire, because 28 AWG is more efficient regarding the transfer of power than 22 AWG with a higher inductance value (Table 2). A voltage regulator component to control the required voltage passed to the mobile device battery for charging with $5 \mathrm{~V}$ to initiate the charging process, as depicted in Figure 6. The purpose of a voltage regulator was to normalize the voltage levels. The voltage regulator steps down the input voltage to the anticipated level and preserves it at a similar level during the supply. This ensures that even when a load is applied, the voltage does not drop.

Table 2. AWG wire inductance comparison [39].

\begin{tabular}{ccccc}
\hline AWG Wire & Wire Diameter $(\mathbf{m m})$ & Loop Diameter $(\mathbf{m m})$ & Relative Permeability & Inductance (H) \\
\hline 21 & 0.7239 & 50 & $1.256 \times 10^{-6}$ & $1.70 \times 10^{-13}$ \\
\hline 22 & 0.6438 & 50 & $1.256 \times 10^{-6}$ & $1.75 \times 10^{-13}$ \\
\hline 24 & 0.5106 & 50 & $1.256 \times 10^{-6}$ & $1.83 \times 10^{-13}$ \\
\hline 26 & 0.4038 & 50 & $1.256 \times 10^{-6}$ & $1.93 \times 10^{13}$ \\
\hline 27 & 0.3606 & 50 & $1.256 \times 10^{-6}$ & $1.98 \times 10^{-13}$ \\
\hline 28 & 0.3211 & 50 & $1.256 \times 10^{-6}$ & $2.02 \times 10^{-13}$ \\
\hline
\end{tabular}

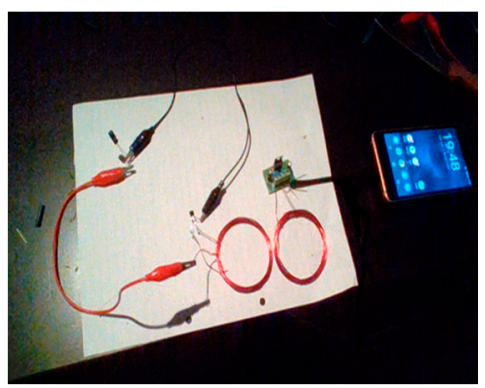

(a)

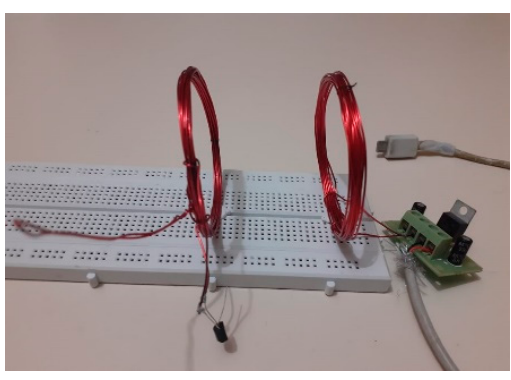

(b)

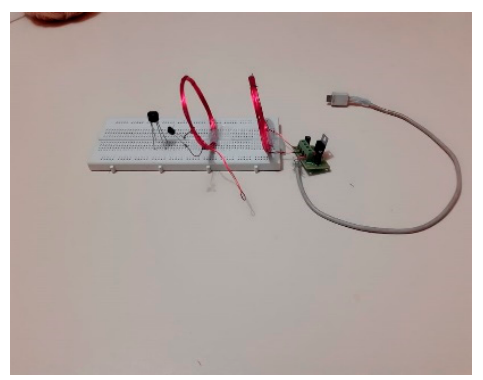

(c)

Figure 6. (a) Prototype circuit with the voltage rectifier connected to the coils. (b) MRC circuit connected to the voltage regulator. (c) MRC coils with the voltage rectifier component.

The voltage $(1.142 \mathrm{~V})$ initially acquired from the RF energy harvesting circuit [30] was too limited for charging the battery of a mobile device. Transferring the power wirelessly would result in some voltage being lost. The RF energy harvesting process with WPT, as shown in Figure 6, is summarized as follows. A capacitor $(100 \mu \mathrm{F}, 16 \mathrm{~V})$ was later included in the RF energy harvesting circuit to store the converted power [30]. Referring to the simulated tests, $6 \mathrm{~V}$ was the estimated input voltage to initiate the charging process. Compared with the experimental results, the RF energy harvested power exceeded that value and provided $9.46 \mathrm{~V}$ to the magnetically coupled circuit for the wireless power transfer to the load for charging. The capacitor was connected to the RF harvesting circuit for $7.5 \mathrm{~h}$. The accumulated voltage stored in the capacitor was $9.46 \mathrm{~V}$. Taking into consideration the average voltage $(6.03 \mathrm{~V})$ flowing through the circuit, this was sufficient for the charging of the mobile device battery. An additional capacitor with the stored charge after rectification (conversion of AC to DC) was connected to the WPT charging circuit. This was sufficient to commence the charging of the battery of a mobile device through the wireless power transfer and in the event of voltage loss across the air gap. It can be concluded based on the results discussed in this research paper that WPT as an alternative form of energy is possible and is readily available for charging the batteries of mobile devices wirelessly. It can be concluded that the higher the harvested energy, the more effective the charging process of the battery of a mobile device. 


\section{Conclusions}

The wireless power transfer is a promising innovation for wireless charging of the battery of a mobile phone using magnetic resonance coupling with radio frequency energy harvesting. This connotation can promote green energy sources and it can make mobile devices self-sustaining. However, there is limited research conducted on utilizing both magnetic resonance coupling and radio frequency energy harvesting for this purpose. The wireless power transfer prototype circuit that is provided in this paper has yielded promising results to consider for the improved physical circuit. The unique contribution of this study is the seamless agglutination of a radio frequency energy harvesting circuit with magnetic resonance coupling to successfully transmit the harvested energy through an air gap to charge the battery of a mobile device.

\section{Patents}

A patent application is pending.

Author Contributions: Conceptualization, N.R. and O.O.O.; methodology, N.R.; software, N.R.; Validation, N.R. and O.O.O.; formal analysis, N.R.; investigation, N.R.; resources, N.R. and O.O.O.; data curation, N.R.; writing—original draft preparation, N.R.; writing—review and editing, N.R. and O.O.O.; visualization, N.R. and O.O.O.; supervision, O.O.O.; project administration, N.R. and O.O.O.; funding acquisition, O.O.O. All authors have read and agreed to the published version of the manuscript.

Funding: This research received no external funding.

Institutional Review Board Statement: Not applicable.

Informed Consent Statement: Not applicable.

Data Availability Statement: Data generated within the study are contained within the article.

Conflicts of Interest: The authors declare no conflict of interest.

\section{References}

1. Yan, Y.; Shi, W.; Zhang, X. Design of UAV wireless power transmission system based on coupling coil structure optimization. EURASIP JWCN 2020, 67, 1-13. [CrossRef]

2. Singh, S.K.; Hasarmani, T.S.; Holmukhe, R. Wireless transmission of electrical power overview of recent Research \& development. Int. J. Comput. Electr. Eng. 2012, 4, 207-211.

3. Tfcbooks. Available online: http://www.tfcbooks.com/tesla/1904-03-05.html (accessed on 3 August 2018).

4. Maxwell, J.C., VIII. A dynamic theory of the electromagnetic field. Philos. Trans. R. Soc. 1865, 155, 459-512.

5. Cannon, B.L.; Hoburg, J.F.; Stancil, D.D.; Goldstein, S.C. Magnetic resonant coupling as a potential means for wireless power transfer to multiple small receivers. IEEE Trans. Power Elect. 2009, 24, 1819-1825. [CrossRef]

6. Introduction to Wireless Power Transfer. Available online: http://www.allaboutcircuits.com/technical-articles/introduction-towireless-power-transfer-wpt/ (accessed on 29 August 2018).

7. Kod, M.; Zhou, J.; Huang, Y.; Hussein, M.; Sohrab, A.P.; Song, C. An approach to improve the misalignment and wireless power transfer into biomedical implants using meandered wearable loop antenna. Hindawi Wirel. Power Transf. 2021, 1-12.

8. Moore, J.; Castellanos, S.; Xu, S.; Wood, B.; Ren, H.; Tse, Z.T.H. Applications of wireless power transfer in medicine: State-of-the-art reviews. Ann. Biomed. Eng. 2019, 47, 22-38. [CrossRef]

9. Kumar, P.; Anand, U.; Chaubey, A.; Ambekar, R.S. Wireless power transfer. Int. Res. J. Eng. Technol. 2017, 4, 1309-1312.

10. Xing, Y.; Pan, H.; Xu, B.; Tapparello, C.; Shi, W.; Liu, X.; Zhao, T.; Lu, T. Optimal wireless information and power transfer using deep q-network. Hindawi Wirel. Power Transf. 2021, 2021, 1-12. [CrossRef]

11. Pratik, U. Design of Capacitive Wireless Power Transfer Systems with Enhanced Power Density and Stray Field Shielding. Master's Thesis, Utah State University, Logan, UT, USA, 2019.

12. Yan, Z.; Li, Y.; Zhang, C.; Yang, Q. Influence factors analysis and improvement method on efficiency of wireless power transfer via coupled magnetic resonance. IEEE Trans. Magn. 2014, 50, 83-86.

13. Beh, T.; Kato, M.; Imura, T.; Hori, Y. Wireless power transfer system via magnetic resonant coupling at fixed resonance frequencypower transfer system based on impedance matching. World Electr. Veh. J. 2010, 4, 744-753. [CrossRef]

14. Sato, M.; Yamamoto, G.; Gunji, D.; Imura, T.; Fujimoto, H. Development of wireless in-wheel motor using magnetic resonance coupling. IEEE Trans. Power Elect. 2016, 31, 5270-5278. [CrossRef]

15. Wang, H.; Shi, G.; Han, C. A free-standing electromagnetic energy harvester for condition monitoring in smart grid. Hindawi Wirel. Power Transfer. 2021, 2021, 1-14. [CrossRef] 
16. Paul, J.L.; Sasirekha, S.; Kumar, D.N.D.; Revanth, P.S. A working model for mobile charging using wireless power transmission. Int. J. Eng. Sci. Technol. 2018, 7, 584-588.

17. Pinto, R.; Bertoluzzo, M.; Lopresto, V.; Mancini, S.; Merla, C.; Pede, G.; Genovese, A.; Buja, G. Exposure assessment of stray electromagnetic fields generated by a wireless power transfer system. In Proceedings of the 9th European Conference on Antennas and Propagation (EuCAP), Lisbon, Portugal, 13-17 April 2015; pp. 1-4.

18. Pehrman, D.; Liu, Y. Design and stray field evaluation of inductive power transfer in electric vehicle charging. In Proceedings of the 2019 Fourteenth International Conference on Ecological Vehicles and Renewable Energies (EVER), Monte-Carlo, Monaco, 8-10 May 2019; pp. 1-6.

19. Pichon, L. Electromagnetic analysis and simulation aspects of wireless power transfer in the domain of inductive power transmission technology. J. Electromagn. Waves Appl. 2020, 34, 1719-1755. [CrossRef]

20. Jaekel, B. Challenges in the EMC standardization of wireless power transfer systems. JET 2019, 12, 11-17.

21. Brown, W.C. Experiments involving a microwave beam to power and position a helicopter. IEEE Trans. Aerosp. Electron. Syst. 1969, AES-5, 692-702. [CrossRef]

22. American Association for the Advancement of Science. Available online: https://www.aaas.org/heinrich-hertz-andelectromagnetic-radiation (accessed on 28 July 2021).

23. Aparicio, M.P.; Bakkali, A.; Pelegri-Sebastia, J.; Sogorb, T.; Llario, V.; Bou, A. Radio frequency energy harvesting-sources and techniques. In Book Renewable Energy-Utilisation and System Integration; Cao, W., Hu, Y., Eds.; IntechOpen Limited: London, UK, 2016; pp. 155-170.

24. Zhang, X.; Grajal, J.; López-Vallejo, M.; McVay, E.; Palacios, T. Opportunities and challenges of ambient radio-frequency energy harvesting. Joule 2020, 4, 1148-1152. [CrossRef]

25. Tran, L.; Cha, H.; Park, W. RF power harvesting: A review on designing methodologies and applications. Micro Nano Syst. Lett. 2017, 5, 1-16. [CrossRef]

26. Velten, K. Mathematical Modelling and Simulation-Introduction for Scientists and Engineers; Wiley: Weinheim, Germany, 2009; pp. 1-8.

27. Jayarahini, J.; Udhayavani, M. Modeling and simulation of memristor using LTSPice. IJARECE 2016, 5, $249-2499$.

28. Kato, M.; Imura, T.; Hori, Y. Study on Maximize Efficiency by Secondary Side Control Using DC-DC Converter in Wireless Power Transfer via Magnetic Resonant Coupling. World Electr. Veh. J. 2013, 6, 858-862. [CrossRef]

29. Power by Proxi. Available online: https://powerbyproxi.com/wireless-power/ (accessed on 18 August 2018).

30. Ramsaroop, N.; Olugbara, O.O.; Joubert, E. Exploring energy harvesting technology for wireless charging of mobile device batteries. In Proceedings of the IEEE-ICTAS, Durban, South Africa, 9-10 March 2017.

31. Panas, A.; Kyarginsky, B.; Maximov, N. Single-transistor microwave chaotic oscillator. In Proceedings of the NOLTA, Dresden, Germany, 17-21 September 2000; pp. 445-448.

32. Roslia, M.A.; Muradb, S.A.Z.; Norizanc, M.N.; Ramlid, M.M. Design of RF to DC conversion circuit for energy harvesting in CMOS 0.13- $\mu \mathrm{m}$ technology. AIP Conf. Proc. 2018, 1883, 1-8.

33. Visintini, R. Rectifiers. In CAS CERN Accelerator School Specialized Course on Power Converters; Daniel, B., Ed.; CERN: Geneva, Switzerland, 2006; pp. 133-183. Available online: https:/ / cdsweb.cern.ch/record/705845/files/CERN-2006-010.pdf (accessed on 30 August 2006).

34. Collado, A.; Daskalakis, S.N.; Niotaki, K.; Martinez, R.; Bolos, F.; Georgiadis, A. Rectifier Design Challenges for RF Wireless Power Transfer and Energy Harvesting Systems. Radio Eng. 2017, 26, 411-417. [CrossRef]

35. Xu, H.; Wang, C.; Xia, D.; Liu, Y. Design of Magnetic Coupler for Wireless Power Transfer. Energies 2019, 12, 3000. [CrossRef]

36. Abou, H.M.; Yang, X.; Chen, W. Magnetically Coupled Resonance WPT: Review of Compensation Topologies, Resonator Structures with Misalignment, and EMI Diagnostics. Electronics 2018, 7, 1-41.

37. Electronics Tutorials. Available online: https://www.electronics-tutorials.ws/resistor/resistivity.html (accessed on 18 August 2018).

38. Diode, Rectifiers, and Power Supplies. Available online: http://uav.ece.nus.edu.sg/ \{\}bmchen/courses/EG1108_Rectifiers.pdf (accessed on 18 August 2021).

39. Wire Gauge Conversion. Available online: https:/ / www.carreracasting.com/charts/wire-gauge (accessed on 25 July 2021). 